\title{
Release of $\beta$-thromboglobulin during the preparation, in vitro storage and cryopreservation of platelet concentrates
}

\author{
M ANN TAYLOR \\ From the National Blood Transfusion Service, South Western Regional Transfusion Centre, Southmead \\ Road, Bristol BS10 5ND
}

SUMMARY Beta-thromboglobulin is a platelet specific protein which is released from platelets during the platelet release reaction. The amount of $\beta$-thromboglobulin released during various conditions of in vitro storage, including cryopreservation, was compared. The results suggest the measurement of $\beta$-thromboglobulin is unlikely to be of use as a quality control assay for monitoring the in vitro viability of stored platelets.

Platelet concentrates (PCS) are now routinely stored in vitro at $22^{\circ} \mathrm{C}$ although there has been much controversy as to whether they should be stored at $4^{\circ} \mathrm{C}, 22^{\circ} \mathrm{C}$ or cryopreserved. None of these storage conditions is ideal. ${ }^{1-9}$

The platelet specific proteins, $\beta$-thromboglobulin $(\beta T G)$, low-affinity platelet factor 4 and platelet factor 4 (PF4), are stored in the alpha granules and are released from platelets during the platelet release reaction which normally occurs after platelet aggregation..$^{10-12} \beta \mathrm{TG}$ appears to be a proteolytic product of low-affinity platelet factor $4^{13}$ while PF4 is secreted as a proteoglycan PF4 complex which dissociates in plasma. ${ }^{14}$ Although PF4 and $\beta$ TG are released during the platelet release reaction, $\beta$ TG is more abundant and has superior stability in vivo to PF4. ${ }^{1516}$ Moore et $^{1 l^{14}}$ reported that no thrombininduced aggregation or release of $\beta$ TG could be detected in preparations of washed platelets after storage for $48 \mathrm{~h}$. However, $\beta$ TG was detected in the supernatant plasma of PCS after $48 \mathrm{~h}$ which suggested that in vitro ageing was accompanied by leakage of platelet constituents. Therefore, in this study the release of platelet specific $\beta$ TG into the supernatant plasma during in vitro storage of PCS at $4^{\circ} \mathrm{C}$ and $22^{\circ} \mathrm{C}$ for $48 \mathrm{~h}$ and in platelets that have been cryopreserved was studied in order to determine the level of release under various in vitro storage conditions.

Accepted for publication 4 January 1983

\section{Material and methods}

PLATELET CONCENTRATE PREPARATION AND STORAGE CONDITIONS

Platelet-rich plasma (PRP) was prepared from fresh whole blood collected from random donors in citrate-phosphate-dextrose (CPD) anticoagulant within six hours of donation by centrifugation at $2900 \mathrm{rpm}(2260 \mathrm{~g})$ for $90 \mathrm{~s}$ at $22^{\circ} \mathrm{C}$ in a Damon PR 6000 centrifuge with interior wind-shielded, swingout head (Damon IEC Ltd, Dunstable, Bedfordshire). Each PRP preparation for storage without cryopreservation was divided into two aliquots, one of which was acidified with $18 \mathrm{ml}$ acid citrate dextrose (ACD; acidified preparations). PCS were prepared by centrifuging the PRP at $3500 \mathrm{rpm}$ $(3000 \mathrm{~g})$ for $20 \mathrm{~min}$ at $22^{\circ} \mathrm{C}$. Thirty $\mathrm{ml}$ of the supernatant was retained with the platelet button. The button was resuspended immediately when acidified platelets were prepared whereas nonacidified preparations were allowed to stand undisturbed at room temperature for $1-1.5 \mathrm{~h}$ before resuspension. ${ }^{17}$ PCS were further subdivided so that two aliquots were obtained from both the acidified and non-acidified preparations. The initial $\mathrm{pH}$ of the acidified preparations was $6.65 \pm 0.1$ and $7.25 \pm$ $0 \cdot 1$ in the case of the non-acidified preparations. The platelet counts (determined using a Technicon Autocounter) were $970 \pm 240 \times 10^{9}$ platelets $/ 1$ for acidified preparations $(n=12)$ and $990 \pm 240 \times$ $10^{9}$ platelets/l for non-acidified preparations $(\mathrm{n}=$ 12). An aliquot of each acidified and non-acidified preparation was stored at $4^{\circ} \mathrm{C}$ and at $22^{\circ} \mathrm{C}$ with rota- 
tion end over end on a platelet agitator (Helmer Labs, marketed by Horwell Ltd, London) for $48 \mathrm{~h}$.

Cryopreservation of platelets in 3\% (wt/vol) glucose $-3 \%(\mathrm{vol} / \mathrm{vol})$ glycerol and in $5 \%(\mathrm{vol} / \mathrm{vol})$ DMSO was carried out as previously described..$^{18}$ Acidified PCS, prepared as above, were divided into two aliquots so that each unit was cryopreserved with both cryoprotective agents.

\section{$\beta$-THROMBOGLOBULIN ASSAY}

$\beta$ TG concentrations were measured using a radioimmunoassay kit (Amersham International Ltd, Amersham, Bucks).

Platelet samples $(2.5 \mathrm{ml})$ were placed in the blood collection tubes provided and the tubes placed on ice for $30 \mathrm{~min}$ prior to centrifugation at $1500-2000$ $g$ for $30 \mathrm{~min}$ at $4^{\circ} \mathrm{C}$. The supernatants were removed and stored in the vapour phase of liquid nitrogen. Two dilutions (in phosphate-buffered saline, PBS, pH 7.3 Dulbecco "A", Oxoid Ltd, London), of each supernatant sample were used in the assay.

The cryopreserved platelets were thawed at $37^{\circ} \mathrm{C}$ in a waterbath and assayed without removal of cryoprotectant.

A maximum releasable $\beta$ TG value in a given PC was obtained by freezing a sample in liquid nitrogen in the absence of cryoprotective agent and thawing at $37^{\circ} \mathrm{C}$. The freeze-thaw process was repeated three times before dilution of the sample $1 / 10$ with PBS $\mathrm{pH} 7 \cdot 3$ containing $1 \%$ (vol/vol) Triton $\mathrm{X}-100$. The sample was sonicated for $30 \mathrm{~s}$ in a sonicator (MSE Scientific Instruments, Crawley, West Sussex). An aliquot of the sonicated sample $(2.5 \mathrm{ml})$ was processed and assayed for $\beta$ TG content as described above.

To determine $\beta$ TG release after thrombininduced platelet aggregation one volume of ACD was added to eight volumes of PC and the sample centrifuged at $900 \mathrm{~g}$ for $15 \mathrm{~min}$ at room temperature in an MSE Minor Centrifuge. The button was resuspended in modified Tyrode's solution $(0.15 \mathrm{M}$ $\mathrm{NaCl}, 3 \mathrm{mM} \mathrm{KCl}, 0.1 \mathrm{M} \mathrm{NaHCO}_{3}, 0.3 \mathrm{mM} \mathrm{NaH}_{2}$ $\mathrm{PO}_{4}, 5 \mathrm{mM}$ glucose $\mathrm{pH} 7 \cdot 35$ ) to give the same platelet count as that of the PC in autologous plasma. In the aggregation assays ${ }^{19}$ an amount of thrombin (human, $10 \mathrm{U} / \mathrm{ml}$ Sigma Chemical Co Ltd, Poole, Dorset) sufficient to give maximum aggregation (approximately $100 \mu \mathrm{l} / \mathrm{ml}$ platelet concentrate) was added. When sedimentation of the aggregate had occurred (approximately $2 \mathrm{~min}$ ) an aliquot of the supernatant material was processed and assayed for $\beta$ TG content as described above.

Statistical analysis of the results was carried out using Student's $t$ test.

\section{Results}

The results obtained for PCS stored at $4^{\circ} \mathrm{C}$ or $22^{\circ} \mathrm{C}$ for $48 \mathrm{~h}$ are shown in Fig. 1. Although significantly less $\beta$ TG was released by the platelets during the preparation of acidified concentrates than during the preparation of concentrates which had not been acidified ( $p<0.001)$, less than $10 \%$ of the maximum releasable $\beta$ TG was detected during preparation of either concentrate. Platelets stored at $22^{\circ} \mathrm{C}$ released significantly more $\beta$ TG than fresh platelets (p $<0.001$; approximately $30 \%$ of the maximum releasable). No significant difference between platelets stored with or without acidification was apparent. There was however, significantly less $\beta$ TG released from acidified platelets stored at $4^{\circ} \mathrm{C}$ (approximately $11 \%$ of the maximum releasable) than from those platelets stored at $4^{\circ} \mathrm{C}$ without

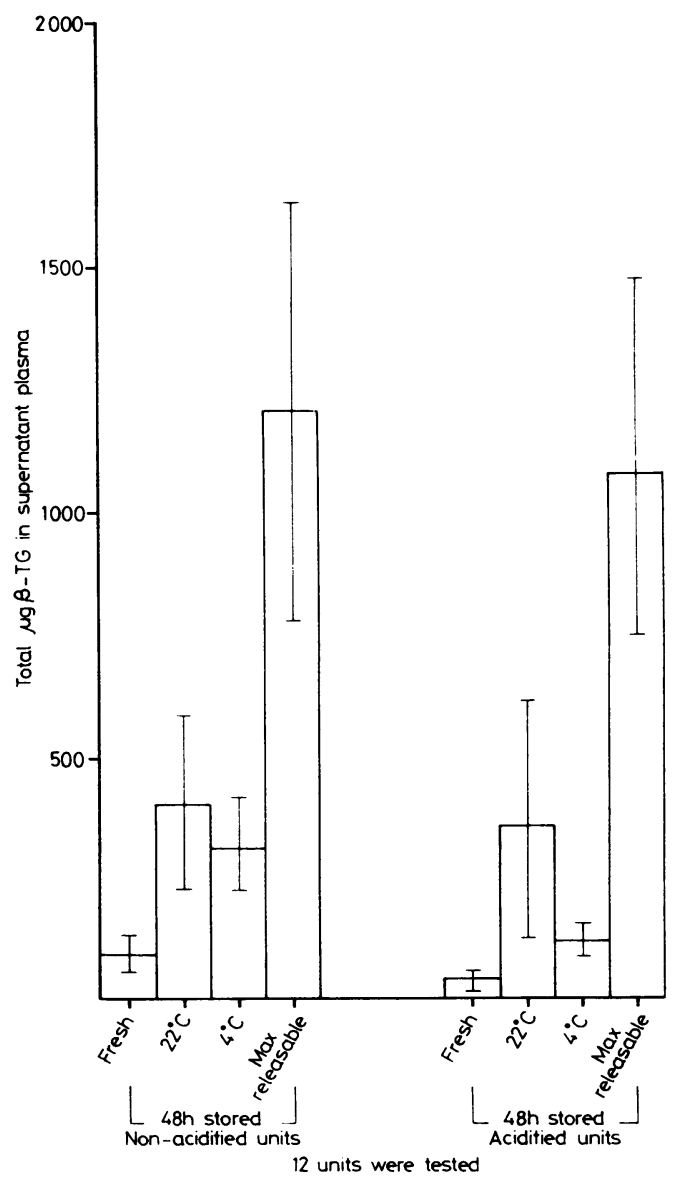

Fig. 1 Total $\beta$-thromboglobulin in platelet preparations prior to and after $48 \mathrm{~h}$ storage at $4^{\circ} \mathrm{C}$ or $22^{\circ} \mathrm{C}$ 
acidification ( $\mathrm{p}<0.001$; approximately $25 \%$ of the maximum releasable).

The results for cryopreserved platelets are shown in Fig. 2. The addition of either cryoprotectant to fresh platelets caused a small release of $\beta$ TG. Cryopreservation in $3 \%$ glucose $3 \%$ glycerol resulted in the release of approximately $24 \%$ of the maximum releasable $\beta$ TG while cryopreservation in $5 \%$ DMSO released only $12 \%$ suggesting that there was more cellular disruption during cryopreservation with $3 \%$ glucose $3 \%$ glycerol than with $5 \%$ DMSO. $\beta$ TG released after cryopreservation in $5 \%$ DMSO with cooling at $1{ }^{\circ} \mathrm{C} / \mathrm{min}$ or by placing in the vapour phase of liquid nitrogen were not significantly different. Thrombin-induced aggregation released only $45 \%$ of the maximum releasable $\beta$ TG.

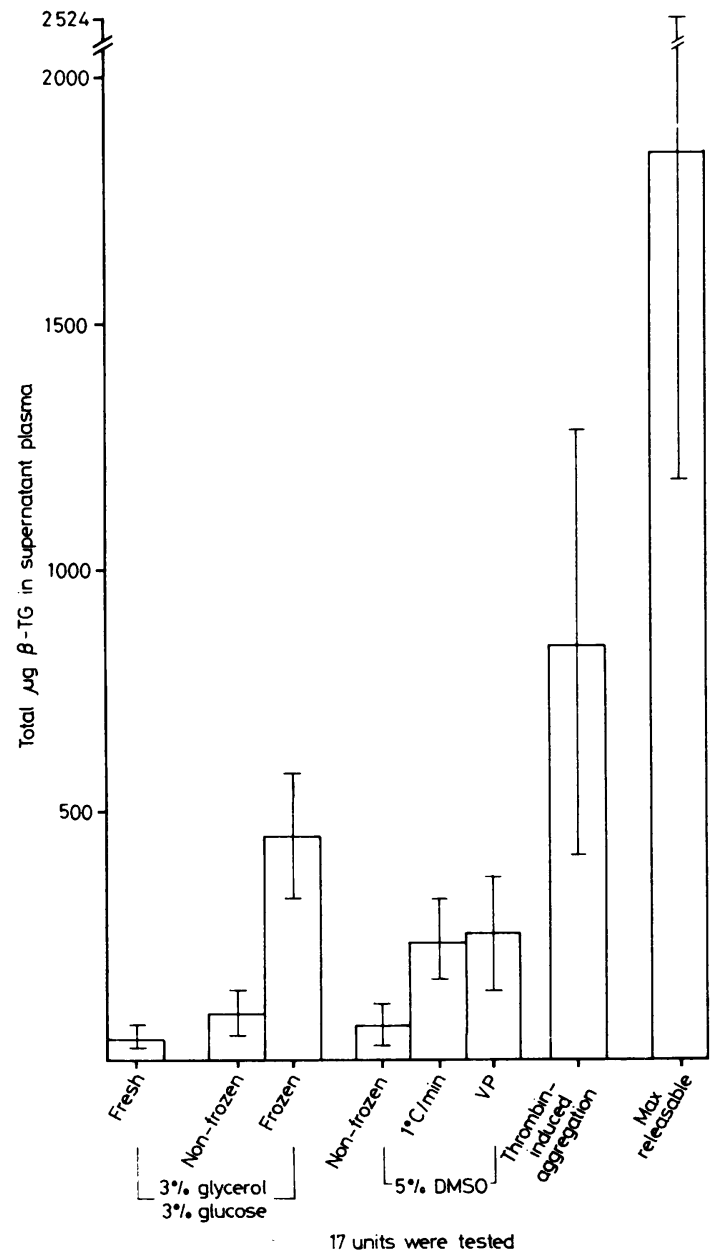

Fig. 2 Total $\beta$-thromboglobulin in platelet preparations prior to and after cryopreservation
Discussion

The $\beta$ TG content of normal platelets has been determined by a number of authors: values of 18 and 45-113 $\mu \mathrm{g} / 10^{9}$ platelets were reported for sonicated washed platelets ${ }^{20}$ and sonicated PRP ${ }^{21}$ respectively while values of $54,{ }^{22} 57 \cdot 1 \pm 10 \cdot 6^{23}$ and $23.5 \pm 0.9 \mu \mathrm{g} / 10^{924}$ platelets were reported for platelets solubilised in $1 \%$ Triton $X-100$. In the present study a value of $102 \pm 37 \mu \mathrm{g} / 10^{9}$ platelets was obtained which is higher than that obtained by others and may indicate that a more substantial disruption of platelet granules was achieved.

Snyder et $a^{24}$ determined the level of $\beta$ TG release during various stages of $P C$ preparation from whole blood collected in either CPD or CPD-adenine-1 anticoagulant. Very little release of $\beta$ TG occurred until the platelet button was resuspended when a substantial increase was observed. The release of $\beta T G$ was found to occur to a greater degree than the leakage of cytosolic lactate dehydrogenase.

PCS prepared as single donor PRP using the Haemonetics model 30 and ACD anticoagulant $(\mathrm{pH}$ 7.08) showed significantly less $\beta$ TG release as compared to age-matched random donor platelets collected in CPD or CPD-adenine-1 (pH 7.17) ${ }^{24}$ However, further work is required to establish whether the results are due to the anticoagulant or the centrifugation conditions and may indicate whether the centrifugation conditions used during platelet preparation significantly influence the release of $\beta$ TG.

The release of three cytoplasmic enzymes (nucleoside diphosphokinase, 3-phosphoglycerate kinase and enolase) during preparation of PCS has been studied by Mourad and Pert ${ }^{25}$ who found that there was a greater release of these enzymes during the preparation of concentrates from whole blood collected in CPD anticoagulant $(\mathrm{pH} \mathrm{7 \cdot 3)}$ than when the anticoagulant was ACD (pH 6.9). Furthermore, reduction of the $\mathrm{pH}$ by addition of extra anticoagulant (pH 6.65) caused a corresponding decrease in the averaged values for the amount of the three enzymes released which is similar to the findings reported here for $\beta$ TG (Fig. 1). Eriksson $e t a^{26}$ reported virtually no PF4 release in PRP prepared

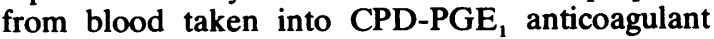
while a minor release was noted in PRP prepared from blood taken into CPD anticoagulant. ${ }^{26}$ These results suggest that $\mathrm{pH}$ and the nature of the anticoagulant used can affect the release of intracellular constituents during PC preparation. However, it has been reported that there is little difference in the in vivo viability of concentrates prepared under the same conditions from PRP in ACD, CPD or acidified ACD anticoagulant. ${ }^{27}$ Thus, although 
measurement of release of $\beta$ TG and other constituents during different methods of platelet preparation may provide evidence of in vitro damage during preparation the extent of this damage is unlikely to be sufficient to affect the in vivo viability.

The results presented here for aliquots of the same $\mathrm{PC}$ stored at $4^{\circ} \mathrm{C}$ and $22^{\circ} \mathrm{C}$ are in agreement with the findings reported for age-matched platelets under similar storage conditions. ${ }^{24}$ However, concentrates stored at $4^{\circ} \mathrm{C}$ for $72 \mathrm{~h}$ release significantly less $\beta$ TG $(p<0.05)$ than concentrates stored at $22^{\circ} \mathrm{C}$ for $72 \mathrm{~h}^{24}$ Platelets are more metabolically active at $22^{\circ} \mathrm{C}$ than at $4^{\circ} \mathrm{C}$ which may account for some increase in release of $\beta \mathrm{TG}$ on storage at $22^{\circ} \mathrm{C}$ rather than at $4^{\circ} \mathrm{C}$.

The results show there was significantly more release of $\beta$ TG during storage of acidified platelets for $48 \mathrm{~h}$ at $22^{\circ} \mathrm{C}$ than at $4^{\circ} \mathrm{C}$ (Fig. 1). The latter storage condition resulted in the least release of $\beta$ TG.

Measurement of PF4 release during preparation of PCS and storage at $22^{\circ} \mathrm{C}$ has shown that only small amounts of PF4 are released during preparation and up to $48 \mathrm{~h}$ storage. ${ }^{26}$ The percentage leakage of the cytosolic protein lactate dehydrogenase was reported lower than the $\beta$ TG release during in vitro storage. ${ }^{24}$

\section{Conclusion}

The release of $\beta \mathrm{TG}$ from platelets stored at $4^{\circ} \mathrm{C}$ and $22^{\circ} \mathrm{C}$ for $48 \mathrm{~h}$ show no correlation with other in vitro and in vivo viability studies. ${ }^{19} 3$

The results obtained here (Fig. 2) show that cryopreservation in 5\% DMSO releases less $\beta$ TG than cryopreservation in $3 \%$ glucose $3 \%$ glycerol and are in general agreement with those obtained previously using other in vitro assays (hypotonic shock response and serotonin uptake) which suggested that $5 \%$ DMSO is the most satisfactory cryoprotective agent. ${ }^{9}$ Comparison of the percentage $\beta$ TG release (relative to the maximal releasable $\beta$ TG) with the yields (based on platelet number ${ }^{9}$ ) obtained after cryopreservation $(24 \%$ and $30 \%$ respectively for $3 \%$ glucose $3 \%$ glycerol; $12.7 \%$ and $54 \%$ for $5 \%$ DMSO with freezing at $1{ }^{\circ} \mathrm{C} / \mathrm{min} ; 13 \%$ and $42 \%$ for $5 \%$ DMSO with freezing in the vapour phase) show that the loss of platelet numbers was much higher than the percentage $\beta$ TG release. This indicates that although platelets are damaged during cryopreservation they do not release all the available $\beta$ TG, presumably a substantial proportion of the $\alpha$-granules remain intact.

These results suggest that while the measurement of $\beta$ TG release may be of limited use for monitoring platelet preparation methods and the disruptive effects of cryopreservation it is unlikely to be of use as a quality control assay for monitoring the in vitro viability of stored platelets.

I thank Dr ID Fraser for his support and encouragement, Dr DJ Anstee for his aid in preparing this paper, Mrs M Clarke for drawing the diagrams and Helen Lane for typing the manuscript.

\section{References}

'International Forum: which are the parameters to be controlled in platelet concentrates in order that they may be offered to the medical profession as a standardised product with specific properties? Vox Sang 1981;40:115-26.

${ }^{2}$ Kattlove HE. Platelet preservation-what temperature? A rationale for strategy. Transfusion 1974;14:328-30.

${ }^{3}$ Slichter SJ, Harker LA. Preparation and storage of platelet concentrates II. Storage variables influencing platelet viability and function. Br J Haematol 1976;34:403-19.

${ }^{4}$ Filip DJ, Aster RH. Relative haemostatic effectiveness of human platelets stored at $4^{\circ} \mathrm{C}$ and $22^{\circ} \mathrm{C}$. J Lab Clin Med 1978;91:618-24.

${ }^{5}$ Handin RI, Valeri CR. Improved viability of previously frozen platelets. Blood 1972;40:509-13.

${ }^{6} \mathrm{Kim}$ BK, Tanoue K, Baldini MG. Storage of human platelets by freezing. Vox Sang 1976;30:401-11.

' Murphy S, Sayar SN, Abdou NL, Gardner FH. Platelet preservation by freezing. Use of dimethylsuphoxide as cryoprotective agent. Transfusion 1974;14:139-44.

${ }^{8}$ Schiffer CA, Aisner J, Wiernik PH. Clinical experience with transfusion of cryopreserved platelets. Br J Haematol 1976;34:377-85.

9 Taylor M Ann. Cryopreservation of platelets: an in vitro comparison of four methods. J Clin Pathol, 1981;34:71-5.

${ }^{10}$ Zahavi J, Kakkar VV. $\beta$-thromboglobulin-a specific marker of in vivo platelet release reaction. Thromb Haemost 1980;44:23-9

"Packham MA, Mustard JF. In vitro methods and the study of platelet mechanisms. Vox Sang 1981;40: suppl 1:22-35.

${ }^{12}$ Kaplan K. $\beta$-thromboglobulin. In: Spaet TH, ed. Progress in haemostasis and thrombosis. New York: Grune and Stratton, 1980;5:153-78.

${ }^{13}$ Niewiarowski S, Walz DA, James P, Rucinski B, Kueppers F. Identification and separation of secreted platelet proteins by isoelectric focusing. Evidence that low-affinity platelet factor 4 is converted to $\beta$-thromboglobulin by limited proteolysis. Blood 1980;55:453-6.

${ }^{14}$ Moore S, Pepper DS, Cash JD. The isolation and characterisation of a platelet specific $\beta$-globulin ( $\beta$-thromboglobulin) and the detection of anti-urokinase and anti-plasmin released from thrombin-aggregated washed human platelets. Biochim Biophys Acta 1975;379:360-9.

is Dawes J, Smith RC, Pepper DS. The release, distribution and clearance of human $\beta$-thromboglobulin and platelet factor 4 . Thromb Res 1978;12:851-61.

${ }^{16}$ Kaplan KL, Nossel HL, Drillings M, Lesznik G. Radioimmunoassay of platelet factor 4 and $\beta$-thromboglobulin: development and application to studies of platelet release in relation to fibrinopeptide A generation. Br J Haematol 1978;39:129-46.

${ }^{17}$ Mourad N. A simple method of obtaining platelet concentrates free of aggregates. Transfusion 1968;8:48.

${ }^{18}$ Herve P, Masse M, Kieffer Y, et al. Cryopreservation des plaquettes dans l'azote liquide en presence de glycerol-glucose. Colloque de cryoimmunologie, Dijon, 1976. INSERM, 62:163-70. 
19 Tandy NP, Taylor MA. Platelet concentrates for transfusion: control of production and storage. Med Lab Sci 1980;37:127-36.

${ }^{20}$ Boughton BJ, Allington MJ, King A. Platelet and plasma $\boldsymbol{\beta}$-thromboglobulin in myeloproliferative syndromes and secondary thrombocytosis. Br J Haematol 1978;40:125-32.

${ }^{21}$ Pareti FI, Dawes J, Franchi F, Mannucci PM, Pepper DS. Content and release of $\beta$-thromboglobulin and platelet factor 4 in patients with qualitative platelet defects. Thromb Res 1979;16:537-42.

${ }^{22}$ Weiss HJ, Witte LD, Kaplan KL, et al. Heterogenicity in storage pool deficiency: studies on granule-bound substances in 18 patients including variants deficient in $\alpha$-granules, platelet factor 4, $\beta$-thromboglobulin and platelet derived growth factor. Blood 1979;54:1296-319.

${ }^{23}$ Bolton AE, Amess JAL, Lekhwani CP, Elliott P. $\beta$-thromboglobulin content of human blood platelets. Scand $J$ Haematol 1980;25:25-9.
${ }^{24}$ Snyder EL, Hezzey A, Katz AJ, Bock J. Occurrence of the release reaction during preparation and storage of platelet concentrates. Vox Sang 1981;41:172-7.

${ }^{25}$ Mourad N, Pert JH. An enzymatic method to determine damage in human platelets. Proc Soc Exp Biol Med 1967;125:643-5.

${ }^{26}$ Eriksson L, Hogman CF, Busch C. Lack of conformity in the behaviour of platelets during normal storage conditions at $22^{\circ}$ C. Vox Sang 1981;40:65-70.

${ }^{27}$ Slichter SJ, Harker LA. Preparation and storage of platelet concentrates 1 . Factors influencing the harvest of viable platelets from whole blood. Br J Haematol 1976;34:395-402.

Requests for reprints to: Mrs M Ann Taylor, National Blood Transfusion Service, South Western Regional Transfusion Centre, Southmead Road, Bristol BS10 5ND, England 